Research Paper

\title{
Analysis of Side Impact Airbag Performance in NASS CDS
}

\author{
Kazuo Higuchi $*^{1)}$ \\ 1) Retired (Honda R\&D/TAKATA)、2-10-14Mita, Meguro, Tokyo, 153-0062, Japan
}

Received on March 29, 2021

\begin{abstract}
Recently the traffic accidents fatality is reducing, but still the fatality of vehicle occupants is large part of them. Vehicle occupants are protected with seatbelt and airbag in frontal crashes and the large effects of them are reported by many researchers, but the report about the side airbag effect was not plentiful, because there was insufficient side impact accident data with new protection device Now almost all cars equipped side airbags and rollover air curtains, and more accident data with side airbags becomes available. The author analyzed US NASS CDS data to investigate the effect of side airbags and head protection rollover air curtains in nearside impact. Results shows the most frequent injury is to the torso regardless of whether the side air bag deployed or not. More study is needed about the effect of rollover air curtain for head/neck injury, and torso air bag has some effect, but it is not the level of seatbelt in frontal crash.
\end{abstract}

KEY WORDS: Safety, Statistical Accident Analysis, Near Side Crash, AIS (abbreviated injury scale), Head/Neck Injury

Torso Injury, Hip Injury, Side Air Bag, risk curve (C1)

\section{Introduction}

There is many fatalities and severe injuries occurring in the side impact, especially near side impact. The first regulatory requirement for the occupant protection in side impact was published on 1980's in U.S.A. as FMVSS214 MDB (Moving Deformable Barrier) test. (See Fig.1) This early stage regulation required only chest injury criteria, which was a function named TTI (thoracic trauma index), and used a 50th percentile adult male test dummy SID which was modified from frontal dummy, and did not use a 5th percentile female dummy in the test. All vehicle manufacturers used interior padding as a countermeasure for that requirement. Then Volvo introduced the first air bag for side impact in $1995 \mathrm{MY}$ Volvo 850. Around that time, the consumer information programs in the world began to include side impact. Then interest to occupant protection in side impact increased, and Side Air Bag installation began increase. But in the real world accidents, fatality and serious injury in side impact was still common

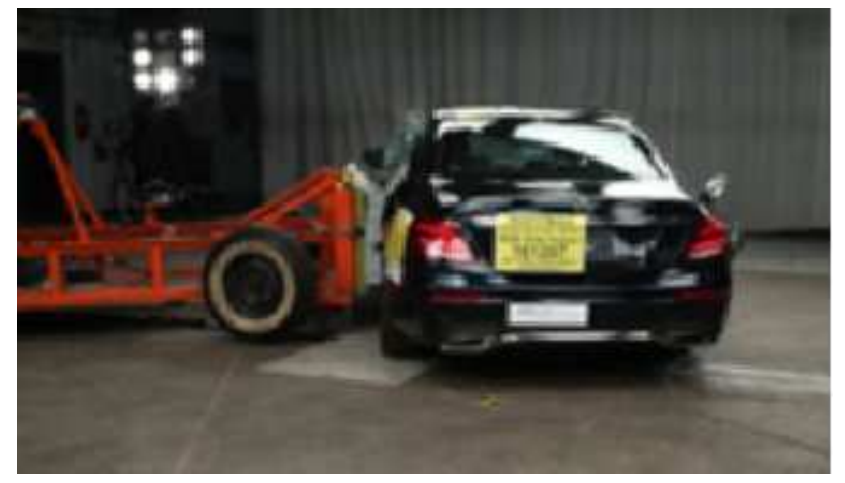

Fig.1 Moving Deformable Barrier Test

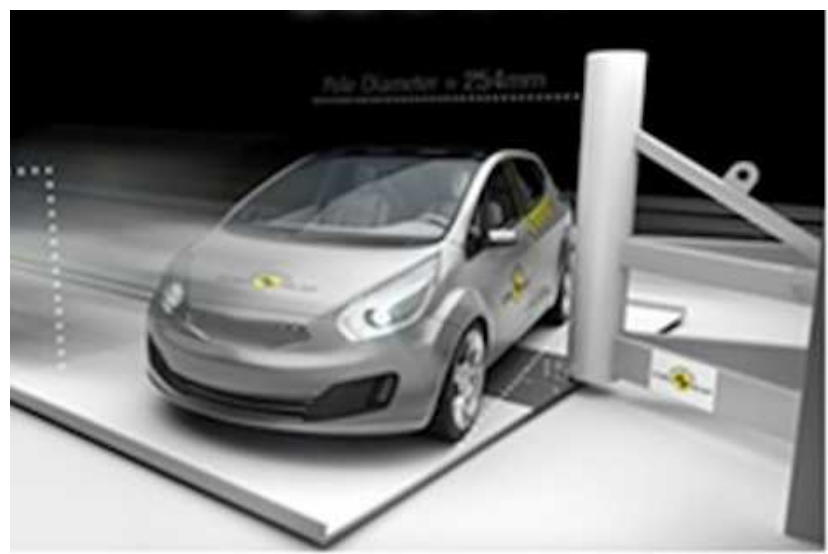

Fig.2 Pole Crash Test

In the 2004 Fatality Analysis Reporting System (FARS), there were 9,270 side impact fatalities. In this situation, 41 percent of the total fatalities are caused by head/face injuries, 34 percent by chest injuries and 6 percent by abdominal injuries. [3]

So NHTSA upgrade the requirement from 2011MY. They added the Pole crash requirement, and also FMVSS 201 Ejection prevention requirement which led to the rollover curtain air bag. (See Fig.2)

Crash test dummies were also changed to ES-2 and SID-IIs, and injury criteria include head, abdomen and pelvis. Also the requirement for chest was changed to deflection and $\mathrm{G}$ at lower spine instead of TTI. The details of the injury criteria are shown in Table 1.

The first air bag for side protection was installed to the inside door panel, and it protected occupant torso. Later the variation of side air

(C2021 Society of Automotive Engineers of Japan, Inc. This is an open access article under the terms of the Creative Commons Attribution-NonCommercial-ShareAlike license. 
Vol.12, No.3(2021)

\begin{tabular}{|l|l|l|l|l|l|}
\hline & HIC36 & $\begin{array}{l}\text { Chest } \\
\text { deflectio } \\
\mathrm{n}(\mathrm{mm})\end{array}$ & $\begin{array}{l}\text { Lower } \\
\text { spine } \\
(\mathrm{g})\end{array}$ & $\begin{array}{l}\text { Abdomi } \\
\text { nal force } \\
(\mathrm{N})\end{array}$ & $\begin{array}{l}\text { Pelvic } \\
\text { force }(\mathrm{N})\end{array}$ \\
\hline ES-2re & 1,000 & $44 \mathrm{~mm}$ & N/A & $2,500 \mathrm{~N}$ & $6 \mathrm{k} \mathrm{N}$ \\
\hline SID-IIs & 1,000 & N/A & $82 \mathrm{~g}$ & N/A & $5,53 \mathrm{k} \mathrm{N}$ \\
\hline
\end{tabular}

Table 1 Injury Criteria

bag increased including rollover curtain air bags to protect head in pole crash and rollover. Also many torso bags were installed not only to door inside panel, but also to the seatback. Side air bag availability increased from late 1990's and around 2010 most new cars were equipped many type of side air bag. Fig. 3 shows US vehicle fleet side air bag increase and type by model year.

Kahane, evaluated the effect of side air bag in 2011. [1] He conducted logistic regression analyses of FARS data through calendar year 2011 showing statistically significant fatality reductions for all types of rollover curtain air bags and torso bags in near-side impacts for drivers and right-front passengers of cars and LTVs. His conclusion is shown in Table 2.

Kahane showed the effectiveness in fatality reduction used FARS data, but FARS cannot provide a detailed evaluation. The data from NASS CDS was not enough at that time due to the small number of side air bags and rollover curtains which were relatively new equipment. Now the data in NASS CDS with side air bags and rollover curtain increased and I tried to evaluate more detail.

\section{US Vehicle Fleet- Airbag Types By Model Year}

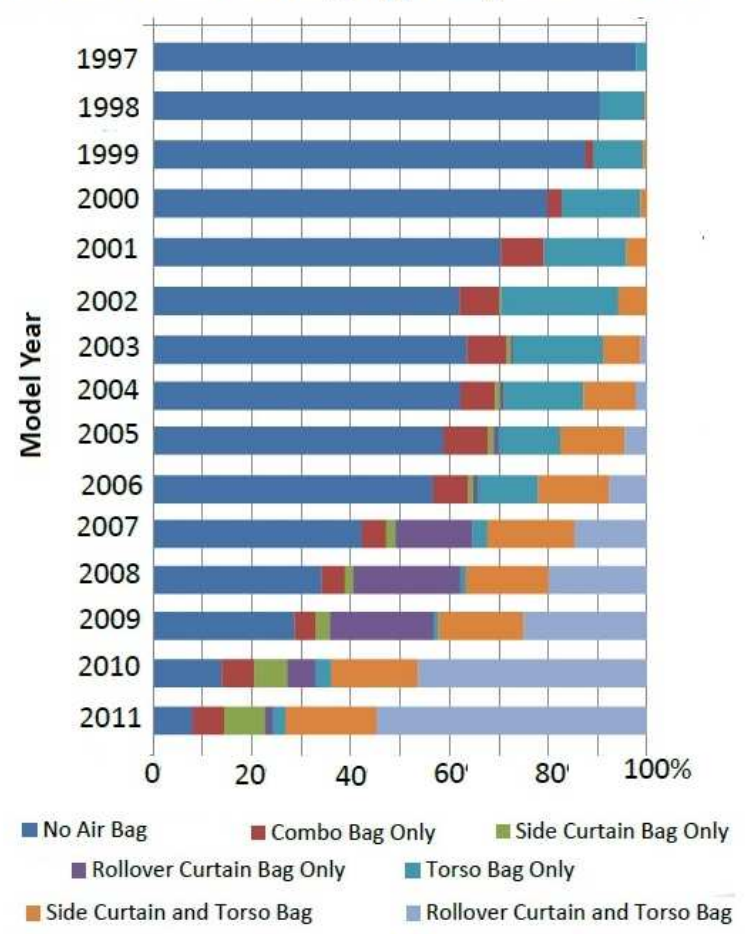

Fig. 3 US Vehicle Fleet-SAB Types by Model Year

$\begin{array}{lrr} & \begin{array}{c}\text { Fatality } \\ \text { Reculction (\%) }\end{array} & \begin{array}{c}\text { Confidence } \\ \text { Bounds }\end{array} \\ \text { Curtains plus torso bags } & 31.3 & 25.0 \text { to } 37.1 \\ \text { Combination bag } & 24.8 & 17.7 \text { to } 31.2 \\ \text { Curtain only } & 16.4 & 3.0 \text { to } 28.0 \\ \text { Torso bag only } & 7.8 & .4 \text { to } 14.7\end{array}$

Table 2 Kahane's conclusion [1]

\section{Method}

Source data: Source data was NASS CDS data from 2008 to 2015, except for the Side Air Bag deployed case, where the range was expanded from 2004 to 2015 . There were insufficient number of deployed cases during the period of 2008 to 2015.

Case: Left side occupant injured with left side vehicle damage and right side occupant injury with right side vehicle damage was selected to get near side impact cases, and rollover was excluded. Only delta $\mathrm{V}$ available case were chosen.

Injury: AIS3 or more (AIS3+) was collected. Injuries are separated into head/neck injury, torso injury and hip injury.

Head/neck injury include the damage to skull, brain, face, cervical spine, concussion and unconsciousness.

Torso injury include fracture of thorax and lumber potion, internal organ damage of chest and abdomen like lung, aorta, heart, spleen, also shoulder, scapula and upper arm are included.

Hip injury include the injury to pelvis portion, and femoral head/neck potion of femur.

Side Air Bag: There are two types of side air bag. One is rollover air curtain which is developed to prevent occupant ejection to outside of vehicle, but it can protect occupant head and neck in side crash also. (See Fig. 4)

The other type is torso bag. There are some variation in torso bag. Some bags are installed to the side of seatback and deployed from there to front direction between occupant and door panel.

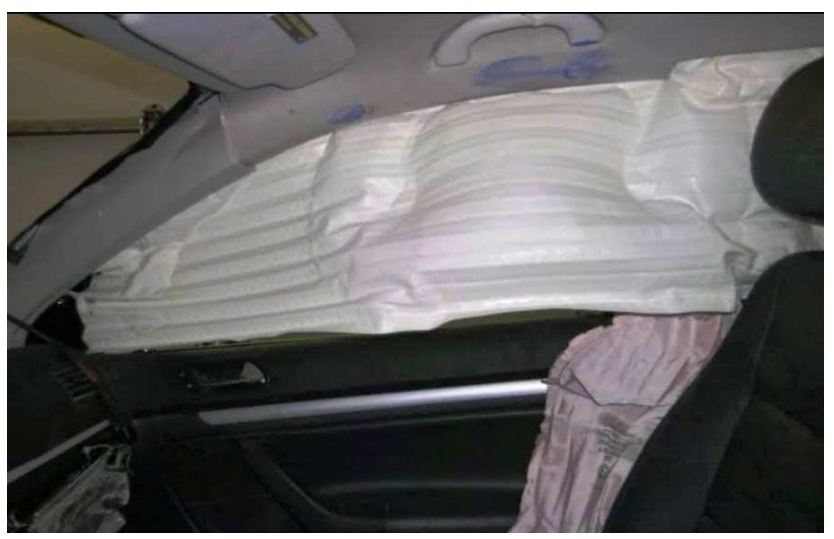

Fig.4 Rollover Curtain Air Bag 


\section{Kazuo Higuchi / International Journal of Automotive Engineering}

Vol.12, No.3(2021)
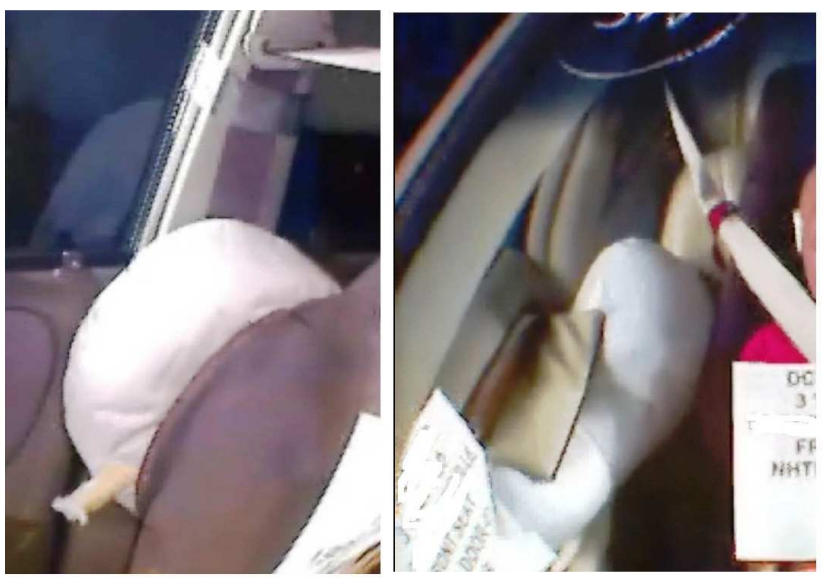

Fig.5 Seatback mount and Door mount Torso bag

Some bags are installed to door panel and deploy between occupant and installed location. (See Fig.5)

Some other variation exist, some bags extended upward to protect not only chest but also head and called combination bag, and other type extended downward to protect not only chest but also hip area. (See Fig.6)

In NASS CDS these air bag type is not indicated directly, but NASS indicate the location of air bag installed. So using installed location the type of air bag can be estimated.

In NASS the installed location is coded as follows.

\section{Code="1 "> Steering Wheel Hub}

This indicates the air bag is Driver air bag for frontal crash

Code $=" 2$ " > Top Instrument Panel

This indicates the air bag is Passenger air bag for frontal crash Code="4 ">Bottom Instrument Panel

This indicates the air bag is Knee air bag for frontal crash

\section{Code $=" 5 \& 12 ">$ Seat Back}

This indicates the air bag is Torso protection air bag installed to seatback for side crash.
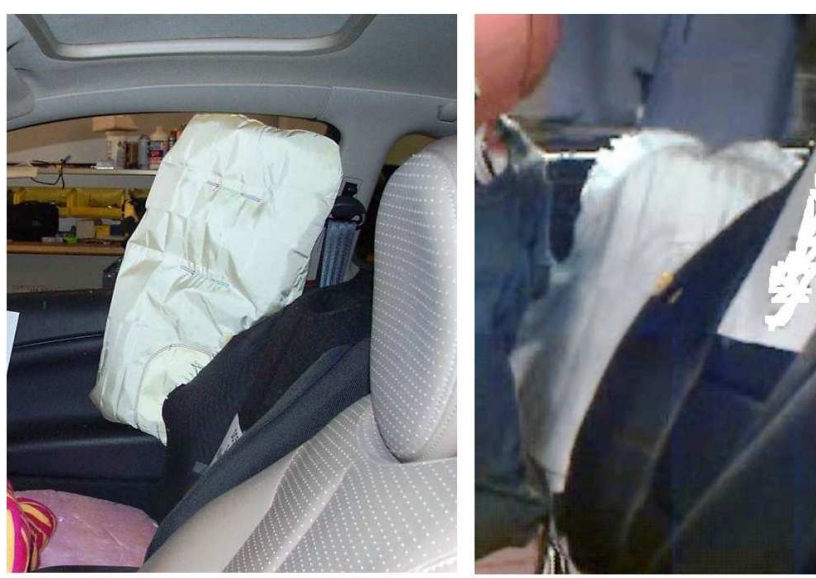

Fig.6 Combination Bag and Torso bag with Hip protection

\section{Code="06 ">Door/Panel}

This indicates the air bag is Torso protection air bag installed to door panel for side crash.

Code="07 ">Roof Side Rail

This indicates the air bag is Rollover curtain air bag for rollover and side crash.

Torso bags and Air curtains can be identified from this information, but the combination bag and torso bag with hip protection cannot be identified, so all air bags installed to seatback and door panel are treated as torso bag.

Data set: For the evaluation of each side air bag, NASS data was collected separately as following six data sets.

1) AIS3 or more Head/neck injury with rollover curtain air bag deployment.

2) AIS3 or more head/neck injury without rollover curtain air bag deployment.

3) AIS3 or more torso injury with torso protection air bag deployment.

4) AIS3 or more torso injury without torso protection air bag deployment.

5) AIS3 or more hip injury with torso protection air bag deployment.

6) AIS3 or more hip injury without torso protection air bag deployment.

Effect of rollover curtain air bag can be evaluated comparing 1) and 2).

Torso injury protection effect of torso air bag can be done comparing 3) and 4).

Hip injury protection effect of torso air bag can be done comparing 5) and 6).

Comparison was made using lateral delta V.

\section{Result}

1) There were 42 cases of Head/Neck AIS3+ injury include 14 fatality cases with Rollover Curtain Air Bag deployment which is installed at side roof rail.

2) There were 114 cases of Head/Neck AIS3+ injury include 22 fatality cases without Rollover Curtain Air Bag deployment.

3) There were 95 cases of Torso AIS3+ injury include 17 fatality cases with torso protection airbag deployment which is installed at seatback or door panel.

4) There were 166 cases of Torso AIS3+ injury include 28 fatality cases without torso protection Air Bag deployment.

5) There were 36 cases of hip AIS3+ injury include 1 fatality case with torso protection Air Bag deployment which is installed at seatback or door panel. 
Vol.12, No.3(2021)

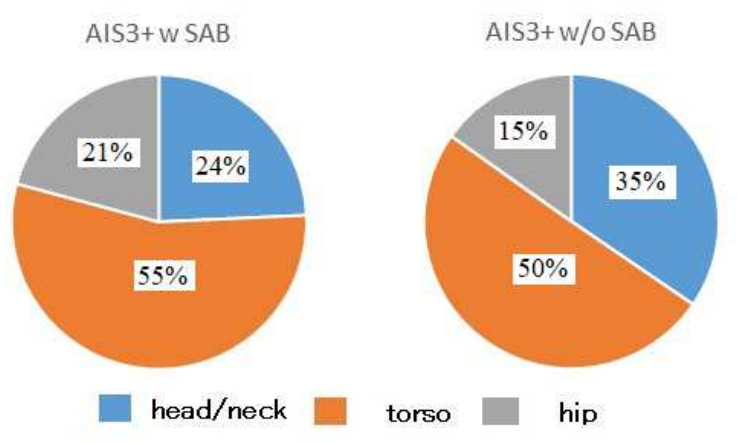

Fig.7 Injury Location of AIS3+ Cases

6) There were 50 cases of hip AIS3+ injury include 3 fatality cases without torso protection Air Bag deployment.

\subsection{Injury location in near side crash cases}

Fig. 7 shows the injury location of AIS3+ cases with side air bag (SAB) deployment and without SAB deployment. The torso is the most frequent AIS3+ injury in both cases. Head/neck AIS3+ injury percentage reduced with $\mathrm{SAB}$ deployment, and with the reduction of head/neck injury, the percentage of torso and hip injuries increased.

Fig. 8 shows Injury location of fatal cases with SAB deployment and without SAB deployment. Both case have similar tendency. Torso Injury is more than half of the cause of death, and Hip has smallest percentage. Also hip injury reduced with side air bag deployment.

Hip injury in fatality cases were reduced in the presence of side air bags, and as a result head/neck and torso injuries percentage increased.

\subsection{Head and Neck Injury}

The mean and standard deviation of lateral delta V of each AIS3+ with Rollover Curtain Air Bag deployment group and without Rollover Curtain Air Bag deployment group is shown in table 3.

T-test (Double sided test) was conducted for comparing mean lateral delta $\mathrm{V}$ between deployed rollover curtain airbag cases and non-deployed rollover curtain airbag cases with statistical significance level of 0.05 .

The results of a t-test analysis with different airbag deployment status are,
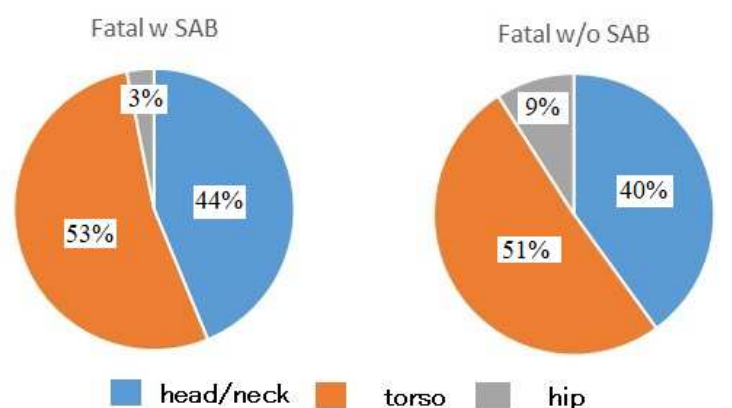

Fig.8 Injury Location of Fatal Cases

\begin{tabular}{|l|l|l|}
\hline $\begin{array}{l}\text { Head and Neck } \\
\text { Injury }\end{array}$ & $\begin{array}{l}\text { Mean Lateral } \\
\text { Delta V }\end{array}$ & $\begin{array}{l}\text { Standard } \\
\text { Deviation }\end{array}$ \\
\hline $\begin{array}{l}\text { with Side Air Bag } \\
\text { deployment }\end{array}$ & $29.57 \mathrm{~km} / \mathrm{h}$ & $18.5 \mathrm{~km} / \mathrm{h}$ \\
\hline $\begin{array}{l}\text { without Side Air } \\
\text { Bag deployment. }\end{array}$ & $30.63 \mathrm{~km} / \mathrm{h}$ & $15.6 \mathrm{~km} / \mathrm{h}$ \\
\hline
\end{tabular}

Table 3 Mean Lateral Delta V of Head/Neck Injury

$\mathrm{P}$ value $=0.72, \quad \mathrm{~T}$ score $=0.36$

The difference between the two groups is not statistically significant.

Fig.9 shows the comparison of head/neck AIS3+ injury risk curve with Rollover Curtain Air Bag deployment and without Rollover Curtain Air Bag deployment. The mean lateral delta V with rollover curtain air bag deployment is $3.5 \%$ lower than the mean lateral delta $\mathrm{V}$ without rollover curtain air bag deployment. This means the cases with rollover curtain air bag deployment have more injury than the cases without rollover curtain air bag deployment.

\subsection{Torso Injury}

The mean lateral delta $\mathrm{V}$ and standard deviation of each AIS3+ injury with torso protection air bag deployment and without Torso protection Air Bag deployment is shown in table 4.

T-test (Double side test) was conducted for comparing mean lateral delta $\mathrm{V}$ between deployed side airbag for torso protection
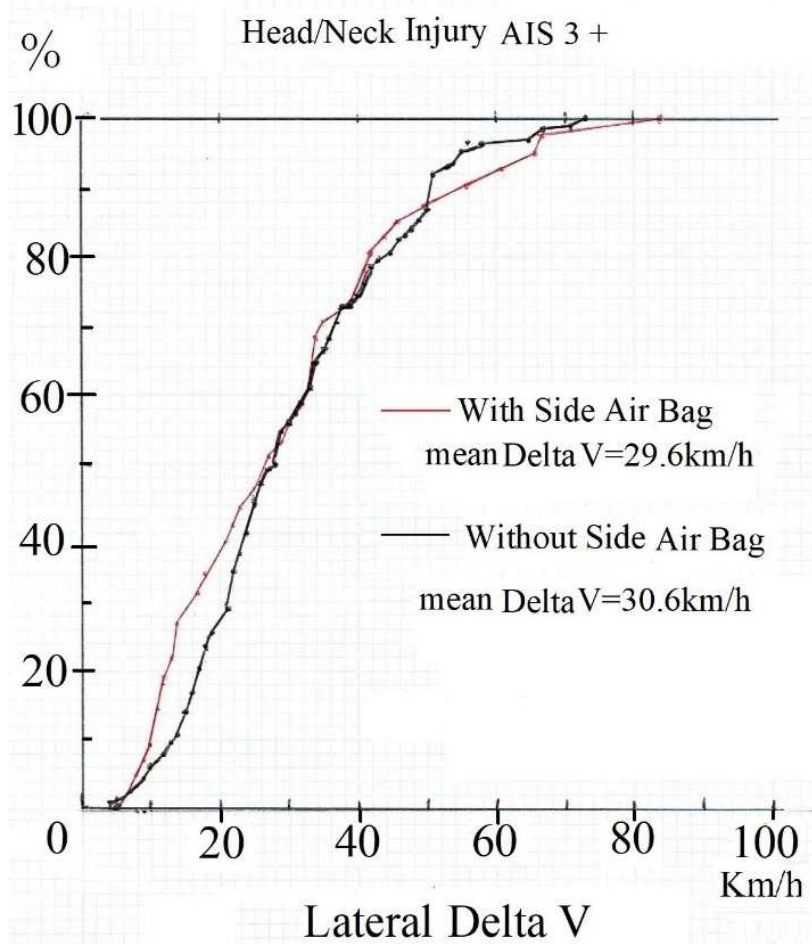

Fig. 9 Head/Neck Injury vs. Lateral Delta V 
Vol.12, No.3(2021)

\begin{tabular}{|l|l|l|}
\hline Torso Injury & $\begin{array}{l}\text { Mean Lateral } \\
\text { Delta V }\end{array}$ & $\begin{array}{l}\text { Standard } \\
\text { Deviation }\end{array}$ \\
\hline $\begin{array}{l}\text { with Side Air Bag } \\
\text { deployment }\end{array}$ & $33.49 \mathrm{~km} / \mathrm{h}$ & $16.8 \mathrm{~km} / \mathrm{h}$ \\
\hline $\begin{array}{l}\text { without Side Air } \\
\text { Bag deployment. }\end{array}$ & $30.27 \mathrm{~km} / \mathrm{h}$ & $14.2 \mathrm{~km} / \mathrm{h}$ \\
\hline
\end{tabular}

Table 4 Mean Lateral Delta V of Torso Injury

cases and non-deployed side airbag for torso protection cases, with statistical significance level of 0.05 . The results of t-test (Double sided test) analysis with different airbag deployment status are, $\quad P$ value $=0.10, \quad$ T score $=1.64$

The difference of this two group is statistically significant.

The mean lateral delta V Torso injury with torso protection airbag deployment case is $3.2 \mathrm{~km} / \mathrm{h}$ higher than no deployment case. This means that AIS3+ injury occurred at $10.6 \%$ higher delta $\mathrm{V}$ in the torso bag deployment cases.

Fig.10 shows the comparison of torso injury risk curve with torso side airbag deployment and without torso side airbag deployment . The difference of two curves is not large in low speed range but it becomes larger when delta $\mathrm{V}$ becomes higher, especially when the lateral delta $\mathrm{V}$ is higher than $50 \mathrm{~km} / \mathrm{h}$.

\subsection{Hip Injury}

The mean lateral delta V and standard deviation of each AIS3+

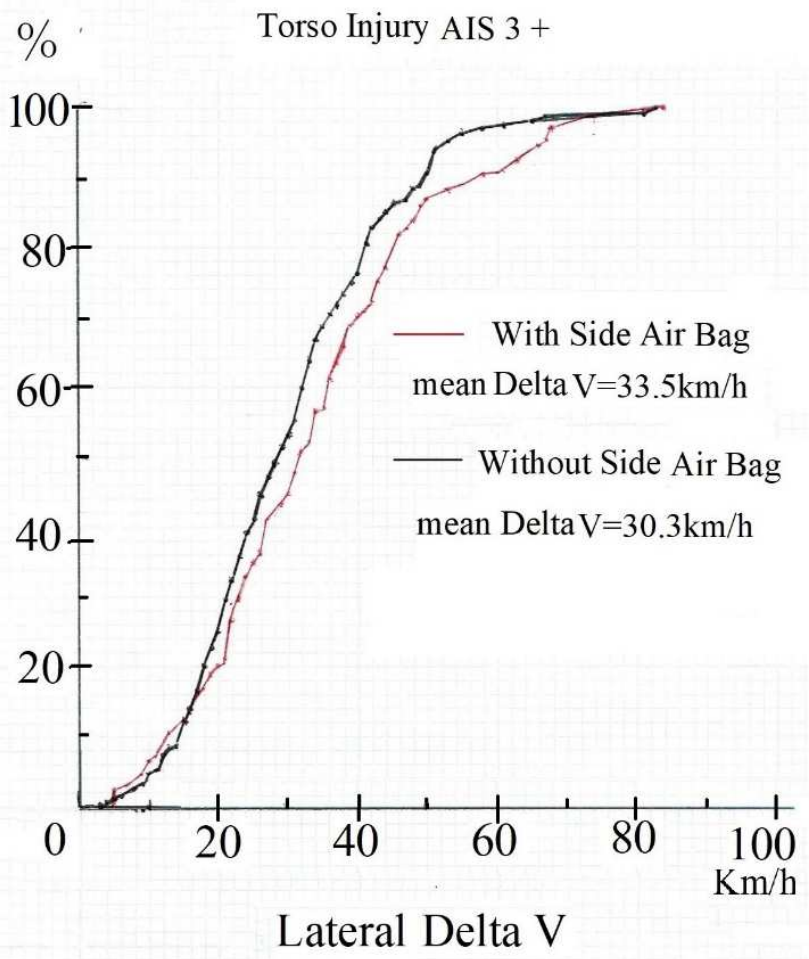

Fig.10 Torso Injury vs. Lateral Delta V

\begin{tabular}{|l|l|l|}
\hline Hip Injury & $\begin{array}{l}\text { Mean Lateral } \\
\text { Delta V }\end{array}$ & $\begin{array}{l}\text { Standard } \\
\text { Deviation }\end{array}$ \\
\hline $\begin{array}{l}\text { with Side Air Bag } \\
\text { deployment }\end{array}$ & $36.06 \mathrm{~km} / \mathrm{h}$ & $17.4 \mathrm{~km} / \mathrm{h}$ \\
\hline $\begin{array}{l}\text { without Side Air } \\
\text { Bag deployment. }\end{array}$ & $30.62 \mathrm{~km} / \mathrm{h}$ & $12.5 \mathrm{~km} / \mathrm{h}$ \\
\hline
\end{tabular}

Table5 Mean Lateral Delta V of Hip Injury

hip injury with Torso protection Air Bag deployment and without Torso protection Air Bag deployment is shown in table 5.

T-test (Double sided test) was conducted for comparing mean lateral delta $\mathrm{V}$ between deployed side airbag for torso protection cases and non-deployed side airbag for torso protection cases, with a statistical significance level of 0.05 .

The results of a t-test analysis of hip injury with different airbag deployment status are,

$P$ value $=0.10, \quad T$ score $=1.69$

The difference of this two group is statistically significant.

The mean lateral delta $\mathrm{V}$ of hip injury with torso protection airbag deployment case is $5.5 \mathrm{~km} / \mathrm{h}$ higher than no deployment case.

Fig.11 shows the comparison of hip injury risk curve with side airbag for torso deployment and without side airbag for torso deployment. The mean delta $\mathrm{V}$ difference between air bag deployment and no deployment shows the air bag deployment improves the protection of hip injury, and the improvement of mean lateral delta $\mathrm{V}$ value is $17.8 \%$. Like the torso injury case the

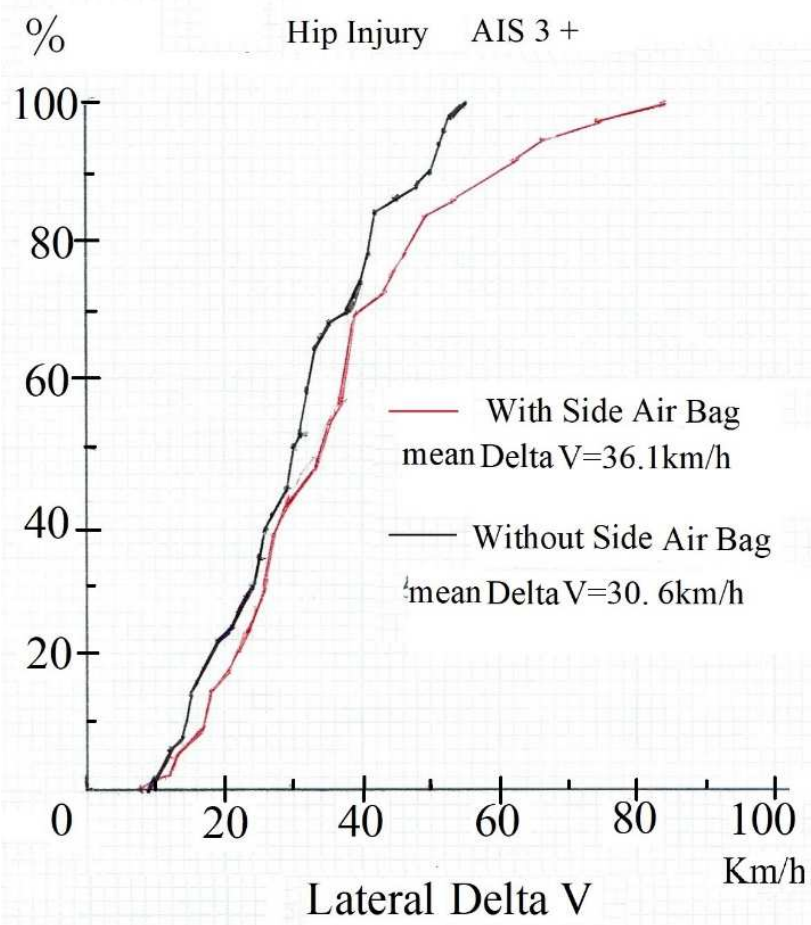

Fig.11 Hip Injury vs. Lateral Delta V 
difference between the two hip injury curves is not large in low speed range but becomes larger when delta $\mathrm{V}$ becomes higher, especially the lateral delta $\mathrm{V}$ is higher than $40 \mathrm{~km} / \mathrm{h}$.

\section{Discussion}

4.1 Injury location in near side crash cases

Comparing AIS3+ injury and fatality case, Head/Neck injury has larger percentage in fatality cases than AIS3+ injury cases. When SAB deployed, Head/neck AIS3+ injury percentage reduced. Torso is the largest part in all scenarios, including AIS3+ injury and fatality, with and without side air bag deployment. The pattern of injury location is not significantly changed with and without the deployment of side air bag.

The pattern of injury location changed completely by seat belt and air bag in frontal crash case, so side air bag in nearside crash do not have large influence on the injury pattern like seat belt and air bag in frontal crash.

\subsection{Head and Neck Injury}

The AIS3+ injury risk curve differences between with and without Side Air Bag head and neck Injury in fig. 9, did not show the effect of Side Air Bag.

This result is quite different from the result of Kahane. [1]

Kahane used data from the FARS (Federal Accident Reporting System) data from 1993 to 2011. He selected near side crashes include 5574 vehicles and conducted Logistic regression analyses showing statistically significant fatality reductions. (Curtain airbag only $=16.4 \%$, Curtains plus torso bags $31.3 \%$ )

To consider the reason of this difference, we have to examine the limitation of the data. In this paper, the author selected lateral delta $\mathrm{V}$ for comparison, and Delta- $V$ comparisons are based on cases where delta- $V$ was calculated, but a large number of crashes lacked this information.

A typical near side crash with head injury is when the vehicle lost control and left the road, crashing into an object off road (ex. Tree) and the delta $\mathrm{V}$ is not available due to the crash with yielding object. So it may be better to add other parameters to use these cases to examine. This will be future work.

The curve in Fig. 9 shows the average speed for injury cases with and without an air curtain is no difference except in low speed. Both curves even, looks similar in speeds higher than $30 \mathrm{~km} / \mathrm{h}$. . There were 63 near side crash cases which had head/neck injury AIS3+ without rollover air curtain deployment under $30 \mathrm{~km} / \mathrm{h}$ lateral delta $\mathrm{V}$, and 27 near side crash cases which had head/neck injury AIS3+ with rollover air curtain deployment under $30 \mathrm{~km} / \mathrm{h}$ lateral delta V. Detailed accident situation may be in need investigate.

\subsection{Torso Injury}

Air bag is effective (statistically significant difference in average delta $\mathrm{V}$ in deployment cases versus non-deployment cases)), but the level of effectiveness looks not large. The curve in Fig. 10 shows the difference becomes slightly larger when lateral delta $\mathrm{V}$ become higher.

Several years ago a group including the author investigated the effect of seatbelt in frontal crash using NASS CDS data from 1993 to 2003. The method is almost same as this paper. AIS3+ with seatbelt and without seatbelt were collected. Also fatal case with seatbelt and without seatbelt are collected.

Result shown in Fig. 12. Delta $\mathrm{V}$ at $50 \%$ risk is $35 \mathrm{~km} / \mathrm{h}$ for AIS3+ unbelted, $43 \mathrm{~km} / \mathrm{h}$ for AIS $3+$ belted. The delta $\mathrm{V}$ of belted case increased $23 \%$ compared to unbelted.

Delta $\mathrm{V}$ at $50 \%$ risk are $50.3 \mathrm{~km} / \mathrm{h}$ for fatal unbelted, $59 \mathrm{~km} / \mathrm{h}$ for fatal belted. The delta $\mathrm{V}$ of belted case increased $17 \%$ compared to unbelted.

In the current study, the $10.6 \%$ increase in delta $V$ for the torso air bag deployment for AIS3+ injury compered to no torso bag is far smaller than $23 \%$ of seatbelt. In fatal case, the reduction by torso bag is only $7.8 \%$ based on Kahane's study, and the delta $\mathrm{V}$ difference of seatbelt case was $17 \%$.

So we have to say the effect of torso protection air bag is not enough to have same level effect of seat belt.

\subsection{Hip Injury}

Fig. 11 shows the risk curve of the side air bag for hip protection. Air bag is effective (statistically significant differences in average delta $\mathrm{V}$ in deployment cases versus nondeployment cases), the mean lateral delta $\mathrm{V}$ increased from 30.6 $\mathrm{km} / \mathrm{h}$ to $36.1 \mathrm{~km} / \mathrm{h}$.

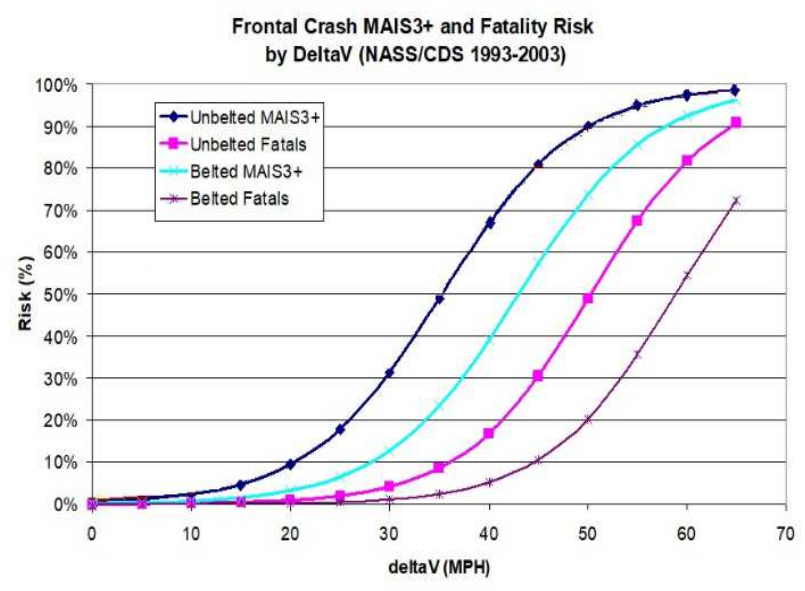

Fig.12 Occupant risk curve in frontal collision 


\section{Kazuo Higuchi / International Journal of Automotive Engineering}

Vol.12, No.3(2021)

This is $18 \%$ increase which is comparable to the effective ness of seatbelt. But the hip injury is not as large a part of AIS3+ injury and fatality as head/neck injury and torso injury.

In fig.7 the percentage of hip injury increased when side air bag deployed, but in fatality case the percentage of hip injury decreased when side air bag deployed.

There is contradiction between these two results. We have to consider the reason of this. Most of pelvis fracture is coded AIS2, so the examining AIS3+ may not be enough, and there were only 31 fatality cases in this study. Also this is affected by the number of head/neck injury, so we have to revisit this when we reexamine head/neck injury.

Regardless fig. 11 shows the side air bag is effective in higher speed. The difference in risk was statistically significant.

\section{Conclusion}

Injuries in nearside impact with and without Side Air Bag were compared using NASS CDS data.

Total of 412 cases with AIS3+ and delta V available, were examined, which include 156 head/neck AIS3+ injury, 261 torso AIS3+ injury and 86 hip AIS3+ injury.

About the injury location, the most frequent AIS3+ injury and fatal injury location is torso, both with torso protection air bag deployed and not deployed.

Next to torso injury is head/neck injury also both with rollover curtain air bag deployed and not deployed, and the percentage of head/neck injuries become larger in fatal cases than AIS3+ injury case.

Hip injury is least, potentially because most hip injury is pelvis fracture which coded AIS2.

Head/Neck injury shows different result from previous study. The reason looks a lot of accident case have missing data for delta $\mathrm{V}$ to evaluate the effect of rollover curtain air bag. So the effectiveness of rollover curtain air bags cannot be evaluate this time and we need more study to evaluate curtain air bag effectiveness for injury.

Torso airbag is a little effective to reduce AIS3+ injury in nearside crash, but it is far less the level of seatbelt effectiveness in frontal crash. Torso protection air bag needs improvement to be more effective.

The torso protection side air bag is effective to reduce hip injury in higher speed and the level is comparable to the effective ness of seatbelt.

\section{Future Work}

1) Head/Neck injury will be reexamined with consideration for the road side object impact for which cannot calculate delta V.

2) Examine different injury level include AIS 2 and/or fatal case
3) Review the influence of age.

\section{Acknowledgement}

The author would like to acknowledge Dr. Kennerly Digges and Dr. George Bahouth, who conduct study which became the base of this study. Also the author acknowledge Dr. Kristy Arbogast and Dr, Richard Kent who send advice for the content of this study.

"This paper is written based on a proceeding which is presented at 2021 JSAE Annual Congress"

\section{References}

[1] Kahane, C. J. (2014, January). Updated estimates of fatality reduction by curtain and side air bags in side impacts and preliminary analyses of rollover curtains. (Report No. DOT HS 811 882). Washington, DC: National Highway Traffic Safety Administration.

[2] Cecilia Sunnevia, Bo Sui, Mats Lindkvist \& Maria Krafft(2015) Census Study of Real-Life Near-Side Crashes with Modern Side Airbag-Equipped Vehicles in the United States, Traffic Injury Prevention, 16:sup1, S117-S124, DOI:

$0.1080 / 15389588.2015 .1022895$

[3] DEPARTMENT OF TRANSPORTATION, National Highway Traffic Safety Administration (2007). Federal Motor Vehicle Safety Standards; Side Impact Protection final rule, 49 CFR Parts 571 and585 [Docket No. NHTSA- 29134]

[4] NHTSA. National Automotive Sampling SystemCrashworthiness Data System. 2011 Analytical Users Manual. Washington, DC: NHTSA,US Department of Transportation; 2012. DOT HS 811675.

[5] Yoganandan N, Pintar FA, Zhang J, Gennarelli TA. Lateral impact injuries with side airbag deployments—a descriptive study. Accid Anal Prev. 2007;39:22-27.

[6] Kathryn L. Loftis, Ashley A. Weaver, Joel D. Stitzel. Investigating the Effects of Side Airbag Deployment in RealWorld Crashes Using Crash Comparison Techniques. Ann Adv Automot Med. 2011 Oct; 55: 81-90. 